\title{
Effect of Sesamum indicum $L$. seed oil supplementation on hepatic and renal mineral concentrations of hypercholesterolemic rats
}

\author{
Ajayi Olubunmi Bolanle, Malachi Oluwaseyi Israel* \\ Department of Biochemistry, Faculty of Science, Ekiti State University, Ado-Ekiti, Nigeria \\ Email address: \\ bunmi_ajayi@yaoo.com (O. B. Ajayi),malachiseyi@gmail.com (O. I. Malachi)
}

\section{To cite this article:}

Ajayi Olubunmi Bolanle, Malachi Oluwaseyi Israel. Effect of Sesamum indicum L. Seed oil Supplementation on Hepatic and Renal Mineral Concentrations of Hypercholesterolemic Rats. American Journal of Life Sciences. Vol. 2, No. 5, 2014, pp. 308-311.

doi: 10.11648/j.ajls.20140205.19

\begin{abstract}
Twenty four male rats weighing between 120-130g were randomly assigned into four groups. Group A was fed normal diet; Group B, C and D were fed hypercholesterolemic diet (i.e. $20 \%$ fat $+1 \%$ cholesterol) for two weeks to establish hypercholesterolemia. Thereafter, Group B were maintained on hyper diet, while C and D were fed 5\% and 10\% Sesamum indicum seed oil supplemented diet for four weeks. The liver and kidney were removed, dried and powdered. The concentrations of iron, zinc, cobalt, manganese, calcium, potassium, magnesium, potassium and sodium were analyzed in both liver and kidney samples with the use of Atomic Absorption Spectrophotometry. Hypercholesterolemia reduced both the hepatic and renal concentrations of sodium, potassium, Phosphorus, magnesium and calcium but reduced the hepatic and not the renal concentrations of manganese and zinc. Supplementation with 5\% but not $10 \%$ Sesamum indicum seed oil reversed the effects and restored the reduced ions concentrations. The hepatic and renal concentrations of Iron and Cobalt ions were not affected by hypercholesterolemia nor by supplementation with Sesamum indicum seed oil.
\end{abstract}

Keywords: Hypercholesterolemia, Sesamum Indicum, Liver, Kidney, Mineral Concentration

\section{Introduction}

Sesamum indicum Linn belongs to the family Pedaliaceae and is grown extensively in tropical and subtropical regions of the world mainly for its oil [1]. Total global amount of seed produced was about 2.8 million metric tons (MT) and that of oil about 1.9 MT in 2002 [2]. India is the largest producer of sesame with approximately $27 \%$ of its production. China, Myanmar, Mexico, Nigeria, Sudan, Bangladesh, Somalia, and Uganda are other major Sesamum indicum producing countries [3]. Several lines of evidence from traditional to modern medicine have confirmed its various medicinal properties $[2,4,5]$. This plant contains significant amount of diverse phytochemicals which have been shown to serve as promising natural antioxidants for both food preservation and medicinal applications [2]. Sesamum indicum L. seed oil, which constitutes about 55\% of the seed [6] is a rich source of mono and polyunsaturated fatty acids [7] and has been appreciated for its antihypercholesterolemic ability $[8,9]$.

Cardiovascular disease is the leading cause of death and is responsible for $27.1 \%$ of global death (WHOa, 2014). Control of cardiovascular risk factors is thus imperative for reducing the morbidity and mortality of the global population [10]. The primary cause of these vascular diseases is atherosclerosis and subsequent formation of lesions inside the coronary and cerebral arteries [11]. Pathogenesis of atherosclerosis is multifactorial and many modifiable and non-modifiable risk factors have been identified [12]. These risk factors collectively contribute to the development, progression and rupture of atherosclerotic plaques [13]. Of the modifiable risk factors of cardiovascular diseases, hypercholesterolemia; which is estimated to cause $4.5 \%$ of global death and $2.0 \%$ of global disability adjusted life years [14], is the most important [15].

Minerals are inorganic nutrients that are required in small amounts for proper metabolic function in plant and animals [16]. Minerals play important roles as component of metalloprotein, as component of bones and teeth and as electrolyte [17]. Since liver serves as the major storage [18], and kidney the excretory organs for minerals [19], studies of alteration of mineral in liver and kidney has been of 
considerable importance in recent years [20]. It has been demonstrated that dietary supplementation with polyunsaturated fatty acids (PUFAs) improves Calcium balance and bone Calcium content in animals and humans [21]. However, the factors associated with liver diseases and mineral metabolism is still vague [22]. Hypercholesterolemia has been reported to decrease circulatory concentrations of sodium and potassium ions [23, 24]. The present study therefore focuses on the change in liver and kidney concentrations of minerals as albino rats induced with hypercholesterolemia were treated with Sesamum indicum seed oil.

\section{Materials and Methods}

Plant material: Benniseed (Sesamum indicum L.) was purchased from Oja-Oba market in Ado-Ekiti. It was identified and authenticated at the Herbarium Section of Plant Science Department, Ekiti State University, Ado-Ekiti, Nigeria. It was cleaned, washed and sundried.

Extraction of oil: Oil was extracted using Soxhlet extractor and n-hexane as the solvent (bpt $40-60{ }^{\circ} \mathrm{C}$ ). The extracted oil was concentrated in a rotary evaporator.

Experimental procedure: Healthy male albino rats were randomly assigned into four groups (A, B, C and D) comprising of six rats each. Group A served as the normal control while group B, C and D served as the test group. Initially, animals in groups (B, C and D) were fed with $20 \%$ fat $+1 \%$ cholesterol for two weeks to establish hypercholesterolemia. Thereafter, rats in groups $\mathrm{C}$ and D were treated with feed supplemented with 5\% and 10\% Sesamum indicum seed oil respectively they were maintained on these dietary regimen for four weeks while being weighed weekly.

Table 1. Diet Compositions ( $\mathrm{kg}-1$ ).

\begin{tabular}{lllll}
\hline & A & B & C & D \\
\hline Corn Starch & 290 & 130 & 280 & 230 \\
Soya Meal & 510 & 510 & 510 & 510 \\
Sucrose & 100 & 100 & 100 & 100 \\
Vitamin-mineral mix & 50 & 50 & 50 & 50 \\
Soya bean oil & 50 & $200(20 \%)$ & - & - \\
Benniseed oil & - & - & $50(5 \%)$ & $100(10 \%)$ \\
Cholesterol & - & $10(1 \%)$ & $10(1 \%)$ & $10(1 \%)$ \\
\hline
\end{tabular}

A -Soya bean oil (positive control)

B $-20 \%$ fat $+1 \%$ cholesterol (negative or hyper control)

C -Beniseed oil (5\%) supplemented diet

D -Beniseed oil (10\%) supplemented diet

Vitamin-mineral mix composition: Vitamin A. 15,000,000, Vitamin b6 2,350mg, Vitamin b12 11,350mg, Vitamin c 100mg, nicotiannite 16,700mg, calcium pantotherate $5,350 \mathrm{mg}$, potassium chloride $87,000 \mathrm{mg}$, sodium sulphate $212,000 \mathrm{mg}$, sodium chloride $50,000 \mathrm{mg}$, magnesium sulphate $12,000 \mathrm{mg}$, copper sulphate $12,000 \mathrm{mg}$, zinc sulphate $12,000 \mathrm{mg}$, manganese sulphate $12,000 \mathrm{mg}$, lysine $\mathrm{HCl} 15,000 \mathrm{mg}$ - metronome $1000 \mathrm{mg}$, exponent Q.S $1000 \mathrm{~g}$.

Tissues preparation: The feeding trial process lasted six weeks after which the rats were anaesthetized with chloroform after they have been fasted overnight and the liver and kidneywere removed, weighed, and oven dried oven dried at
34-350C for 7 days and powdered.

Biochemical analysis: Powdered dried samples were digested in nitric acid and then dissolved in deionized water. The concentrations of iron, zinc, cobalt, manganese, calcium, magnesium, potassium and sodium were analyzed with the use of Atomic Absorption Spectrophotometer. Phosphorus analysis required burning in excess of oxygen gas before digestion.

Statistical analysis: The results are expressed as mean \pm S.D. Analysis of variance was used to test for differences in the groups. Differences were considered to be statistically significant at $\mathrm{P}<0.05$. The diet composition is shown in Table 1.

\section{Result and Discussion}

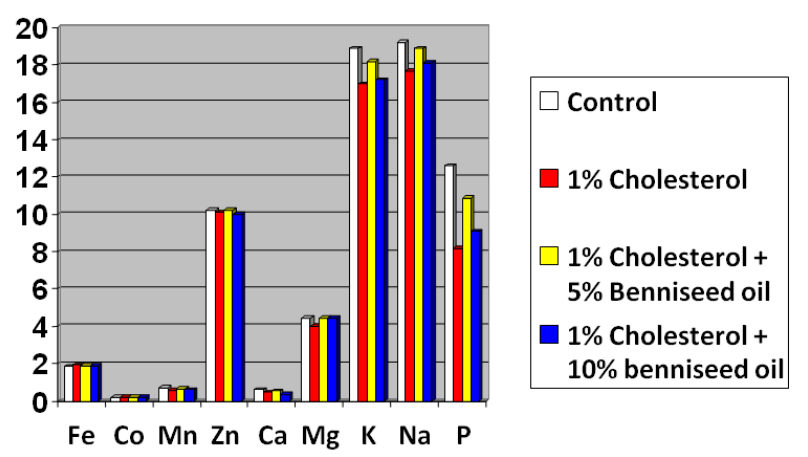

Figure 1. Liver Mineral Concentrations (In Mg/g) Of Hypercholestesterolemic Rat Supplemented With Benniseed Oil.

The antihypercholesterolemic effects of Sesamum indicum seed oil has been demonstrated by Sedigheh and co worker [9]; as it was shown to maintain normal circulatory levels of apoA and apoB, SGOT, SGPT, glucose and insulin and by Ajayi and co-workers [8]; as it was shown to significantly decrease TC, TG, LDL and LDL/HDL ratio and significantly increase the HDL-C in experimental animals induced with hypercholesterolemia. This study however focuses on the change in liver and kidney concentrations of minerals as albino rats induced with hypercholesterolemia were treated with Sesamum indicum seed oil.

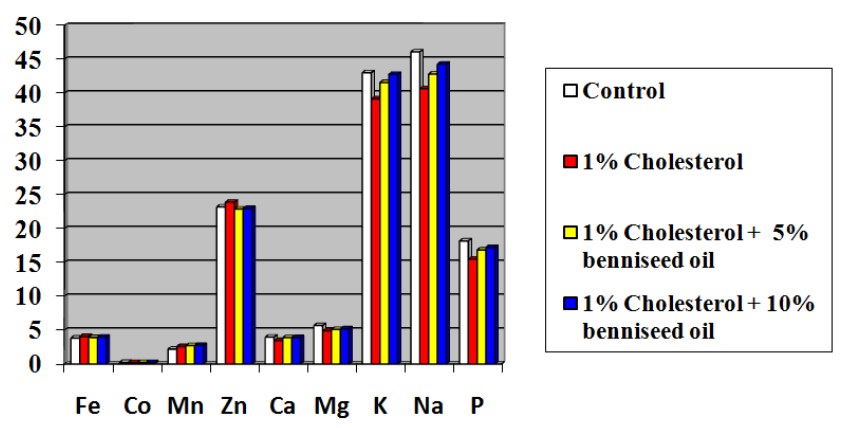

Figure 2. Kidney Mineral Concentrations (In $\mathrm{Mg} / \mathrm{G}$ ) Of Hypercholestesterolemic Rat Supplemented With Benniseed Oil.

Sodium and potassium ions being the most predominant 
cations in the extracellular and intracellular fluids respectively [25], presents the highest concentrations both in the liver and the kidneys; as depicted correspondingly in Figures 1 and 2. Hypercholesterolemia has been reported to decrease circulatory concentrations of sodium and potassium ions [23, 24]. This is consistent with results obtained in the present study as hypercholesterolemia induced by $1 \%$ cholesterol in diet significantly decrease the liver and kidney concentrations of both ions as indicated in Figures 1 and 2 respectively. Administration of Sesamum indicum oil reversed the effect and increased the declining ions concentrations; with a more pronounced increment observed in group fed with 5\% Sesamum indicum oil. Sodium is important to the body because it is necessary for transmission of nerve impulses, heart activity and complementarily with potassium helps in maintaining fluid and electrolyte balance in the body [26, 27]. Phosphorus concentration, both in the liver and kidney, followed the same trend: was reduced by hypercholesterolemia and increased by supplementation of with Sesamum indicum oil. Phosphorus is not as concentrated in both organs as sodium and potassium but its required by all forms of life as it plays a role as a component nucleic acids, nucleotides, phosphorylated reaction intermediates, stiffening of bones and as a component of membrane [16, 28]. About $70 \%$ of phosphorus in the body is organic and $30 \%$ inorganic phosphates [29].

Other minerals that followed the same trend, though to lesser extent, in both organs as did sodium; potassium and phosphorus were magnesium and calcium. Magnesium is essential for every form of life and is present in every cell type [30-32]. ATP, the main source of energy in cells, must be bound to a magnesium ion in order to be biologically active [33]. Calcium plays an important role in signal transduction pathways, where they act as a second messenger [34, 35]. Calcium ions are stored largely in bones and are released from bone into the bloodstream under controlled conditions when need arises [34, 35]. This may be in part the explanation for the relatively low response of calcium concentrations in both liver and kidneys to hypercholesterolemia. Other minerals with the same trend in the liver but not kidney are Manganese and Zinc, both of which are essential trace minerals [36]. The liver and kidney concentrations of Iron and Cobalt ions were not affected by hypercholesterolemia nor by supplementation with Sesamum indicum oil.

\section{Conclusion}

Findings arising from the present studies affirm that the treatment of hypercholesterolemia with Sesamum indicum oil poses no threat to hepatic and renal electrolyte concentration and complementarily with previous studies corroborate the antihypercholesterolemic actions of Sesamum indicum and the possibility of the use of Sesamum indicum oil in the management of clinical conditions associated with hyperlipidemia and hypercholesterolemia.

\section{References}

[1] Arundhati B., Pubali D. and Santinath G. (2010). Antihyperlipidemic Effect of Sesame (Sesamum indicum L.) Protein Isolate in Rats Fed a Normal and High Cholesterol Diet. J. Fd. Sc. 75(9): 274-279.

[2] Namiki, M. (2007). "Nutraceutical functions of sesame: a review," Crit. Rev.Fd.Sc.and Nutr. 47(7) pp. 651-673.

[3] Deshpande S. S., Deshpande S. U. and Salunkhe D. K. (1996). Sesame oil. In: Hui YH, editor. Bailey's Industrial Oil \& fat Products. New York: A Wiley-Interscience Publication. Vol 2. pp 457-459.

[4] Kapoor, L.D. (2001). Hand Book of Ayurvedic Medicinal Plants, CRC Press, New York, NY, USA, 2001.

[5] Gauthaman K. and Saleem T.S.M. (2009). "Nutraceutical value of sesame oil," Pharmacognosy Rev. 3 (6): 264-269.

[6] Abou-Gharbia, H. A., Shahidi, F., Shehata, A. A. Y. and Youssef, M. M. (1997). Effects of processing on oxidative stability of sesame oil extracted from intact and dehulled seeds. J. Am. Oil Chem. Soc. 74(3): 215.

[7] Roma, R. B., Tabekhia, M. M. and Williams, J. D. (1979), "Phytate and oxalate contents in sesame seed (Sesamum indicum L.)," Nutr. Rep. Int. 20(1) pp. 25-31.

[8] Ajayi, O. B., Braimoh, J. and Olasunkanmi, K. (2012). Response of Hypercholesterolemic Rats to Sesamum indicum Linn Seed Oil Supplemented Diet. J. Life Sc. 6: 1214-1219.

[9] Sedigheh A, Mahmoud R. K., Somayeh N., Esfandiar H., and Amirhossein S. (2013). Antihyperlipidemic Effects of Sesamumindicum L in Rabbits Fed a High-Fat Diet. Hindawi Publishing Corporation. The Scientific World Journal Volume 2013, Article ID 365892, http://dx.doi.org/10.1155/2013/365892.

[10] Levenson J. W., Skerrett P. J. and Gaziano J. M. (2002). Reducing the global burden of cardiovascular disease: the role of risk factors. Prev. Cardiol. 5(4): 188-99.

[11] Lloyd-Jones D., Adams R. J., Brown T. M. (2010). "Heart disease and stroke statistics-2010 update: a report from the "American Heart Association," Circulation. 121(7): 948-954.

[12] Joshi, S.C. (2005). "Plant and plant products used as hypolipidaemic/antiatherosclerotic agents: an overview," Proceeding of Zoological society of India, Vol. 4, pp. 27-33.

[13] Souza TD, Mengi SA, Hassarajani S, Chattopadhayay S (2007) "Efficacy study of the bioactive fraction (F-of Acorus calamus in hyperlipidemia," Indian Journal of Pharmacology, vol. 39, no. 4, pp. 196-200.

[14] World Health Organization (2014). Raised Cholesterol. Global Health Observatory -risk factors. http://www.who.int/gho/ncd/risk factors/cholesterol text/en/ (Assesed on: 6/10/2014).

[15] Steinberg D. (2002). Atherogenesis in perspective: hypercholesterolemia and inflammation as partners in crime. Nat. Med; 8: 1211-1217.

[16] Nelson D. L. and Cox M. M. (2000). "Lehninger, Principles of Biochemistry" 3rd Ed. Worth Publishing: New York. pp. 1200. 
[17] McDowell L. E. (2003). Minerals in animal and human nutrition. 2nd ed. Amsterdam: Elsevier Science: 1-630.

[18] Stryer L. (1995). Biochemistry. 4th edition. New York: W. H. Freeman. ISBN 0716720094.

[19] Tolle H. G., Manz F., Diekmann L., Kalhoff H. and Stock G. J. (1991). Effect of renal net acid excretion of various mineral contents in the three lots a common pre-term formula. J Trace Electrolytes Health Dis. 5(4):235-238.

[20] Magda S. M., Madiha M. A. and Seham S. K. (2011). Effect of dietary garlic and onion on liver and tibial mineral concentration in omega-3 fatty acid rich oil fed rats. Agric. Biol. Am. 2(5): 745-751.

[21] Poulsen, R. C., Moughan, P. J. and Kruger, M. C. (2007). Longchain polyunsaturated fatty acids and the regulation of bone metabolism. Exp Biol Med; 232: 1275- 88.

[22] George, J. (2006). Mineral metabolism in dimethylnitrosamine-induced hepatic fibrosis. Clinical Biochemistry 39:984-991.

[23] Dimeski G., Mollee P., Carter A. (2006). Effects of Hyperlipidemia on Plasma Sodium, Potassium, and Chloride Measurements by an Indirect Ion- Selective Electrode Measuring System.Clinical Chemistry 52, No. 1 pp 155-156.

[24] Gross V., Flemming B., Roloff D. and Birkhahn H. J. (1982). [Carbohydrate tolerance and intracellular sodium concentration in rabbits with dietary hypercholesterolemia]. Dtsch Z Verdau Stoffwechselkr; 42(4):169-76.

[25] Terry J. (1994). The major electrolytes: sodium, potassium, and chloride. J Intraven Nurs. 17(5):240-7.

[26] Clausen, M. J. V. and Poulsen H. (2013). "Chapter 3 Sodium/Potassium Homeostasis in the Cell". In Banci, Lucia (Ed.). Metallomics and the Cell. Metal Ions in Life Sciences 12. Springer. doi:10.1007/978-94-007-5561-13. ISBN 978-94-007-5560-4. electronic-book ISBN 978-94-007-5561-1 ISSN 1559-0836 electronic-ISSN 1868-0402.
[27] Pohl H. R., Wheeler J. S. and Murray H. E. (2013). "Chapter 2. Sodium and Potassium in Health and Disease". In Astrid Sigel, Helmut Sigel and Roland K. O. Sigel. Interrelations between Essential Metal Ions and Human Diseases. Metal Ions in Life Sciences 13. Springer. pp. 29-47.

[28] Greenwood N. N. and Earnshaw A. (1997). Chemistry of the Elements (2nd Edn.), Oxford: Butterworth-Heinemann. ISBN 0-7506-3365-4.

[29] Bernhardt, N. E. and Kasko, A. M. (2008). Nutrition for the Middle Aged and Elderly. Nova Publishers. p. 171. ISBN 1-60456-146-7.

[30] Leroy J. (1926). "Necessite du magnesium pour la croissance de la souris". ComptesRendus de Seances de la Societe de Biologie 94: 431-433.

[31] Lusk J.E., Williams R.J.P. and Kennedy E.P. (1968). "Magnesium and the growth of Escherichia coli". Journal of Biological Chemistry 243 (10): 2618-2624. PMID 4968384.

[32] Marschner H. (1995). Mineral Nutrition in Higher Plants. San Diego: Academic Press. ISBN 0-12-473542-8.

[33] Ko Y. H., Hong S. and Pedersen P. L. (1999). Chemical mechanism of ATP synthase. Magnesium plays a pivotal role in formation of the transition state where ATP is synthesized from ADP and inorganic phosphate. J Biol Chem. 274(41):28853-6.

[34] Brini, M., Ottolini, D., Calì, T. and Carafoli, E. (2013). Calcium in Health and Disease". In:Interrelations between Essential Metal Ions and Human Diseases, Metal Ions in Life SciencesAstrid Sigel, Helmut Sigel and Roland K. O. Sigel.eds. 13. Springer. pp. 81-137.

[35] Brini M., Call T., Ottolini D. and Carafoli E. (2013). "Intracellular Calcium Homeostasis and Signaling". In Banci, Lucia (Ed.). Metallomics and the Cell. Metal Ions in Life Sciences 12. Springer.

[36] Schauss A. G. (1996). Minerals, Trace Elements and Human Health. Life Sciences Press: Tacoma (WA). 